\title{
VIRTUAL REALITY FOR CULTURAL HERITAGE TOURISM
}

\section{Çizel Beykan, Ajanovic Edina}

Akdeniz University, Antalya, Turkey
Correspondence:

Çizel Beykan

e-mail:

beykan@akdeniz.edu.tr

\begin{abstract}
:
Cultural Heritage, both tangible and intangible, represents value systems, beliefs, traditions and lifestyles of one society which is being transmitted from one generation to another. Development of Information and Communication Technologies has affected multidisciplinary work on management, protection and promotion of cultural heritage, as well as how it should be taught and used as a touristic product. The aim of current study is to examine the benefits of one of the latest technological developments, Virtual Reality applications (VR applications), in the context of cultural heritage tourism. Accordingly, benefits of VR applications for cultural heritage tourism are summarized under three headings in terms of planning and management of cultural heritage potential for tourism management, marketing and accessibility.
\end{abstract}

Keywords:

Cultural Heritage, Tourism, Virtual Reality

\section{INTRODUCTION}

Cultural Heritage is an expression of a lifestyle, developed by a society and transmitted from generation to generation, which includes tradition, production, space, object, artistic expression and values. It is generally assessed as Tangible and Intangible Cultural Heritage (ICOMOS, 2002). Cultural Heritage represents value systems, beliefs, traditions and lifestyles as part of human activity. As an integral and important part of one culture, it includes visible traces of one society, from ancient times until recent history.

Technological developments have affected multidisciplinary work on management, protection and promotion of Cultural Heritage, as well as how it should be taught and used as a touristic product. Information and Communication Technologies (ICTs) are presenting new opportunities for protection, restoration and spread of Cultural Heritage. Digitalization of data, database storage, and applications such as Internet, social media, artificial intelligence, augmented and virtual reality are significantly contributing to the work on cultural heritage. In the current paper benefits of Virtual Reality applications (VR applications) in the context of cultural heritage tourism is being examined.

Definitions of VR differ due to the efforts to explain the various features that are deemed necessary to create a virtual reality experience. 
Generally, VR is being defined as the virtual environment created by the computer, where people can act and interact. With virtual reality technology users have the ability to walk, move, discover, interact, choose and move objects - all in real time. Parallel with the technological development, virtual reality systems are able to deliver high quality data of user's emotions. VR experience is being affected by two factors: at what level is the technology user isolated from the real world and psychological presence capacity.

Virtual Reality has brought many beneficial applications into tourism industry. Nowadays, parallel with the ICTs development, VR has been used in many areas such as planning, management, marketing and operation. With VR applications tourists can walk around and discover museums in virtual environment. Through virtual travel agencies customers can now participate in virtual tours and use travel guiding services.

In the current paper, effects of virtual reality applications in the context of cultural heritage tourism are being discussed. Cultural heritage tourism can be defined as touristic activities that are being performed under tourists' motivation to learn about local culture and cultural heritage of visited destination. The use of VR as a protection tool is based on the potential to create virtual experiences that tourists can accept as a substitute for a genuine visit to the areas of threatened cultural heritage. It may be desirable to limit the number of tourists in order to manage protected areas such as protected natural and cultural heritage sites. Therefore, VR can be considered as a valuable contribution to environmental sustainability (Dewailly, 1999). Regarding tourism, audiovisual aspects of virtual realities are probably the most important ones. For example, virtual creation, detailed images and sounds regarding one tangible or intangible cultural heritage in museum inventory could be very attractive for tourists. Nowadays it is even possible to add smell, specific for the environment that is to be intensified in virtual reality. In addition, virtual reality tours used for promotion of tourist destinations may increase the demand for this place. Virtual environments with immersive virtual reality capacity can be extremely effective on tourists' intention to visit. In the continuation, the benefits of virtual reality applications for cultural heritage tourism are summarized under three concepts in terms of planning and management of cultural heritage potential for tourism management, marketing and accessibility.

\section{BENEFITS OF VR APPLICATIONS FOR CULTURAL HERITAGE TOURISM}

The qualities of VR allow for the visualization of tangible and intangible elements of cultural heritage. It can be used as a valuable tool for urban, environmental and architectural planning purposes in the context of tangible cultural heritage (Cheong, 1995). VR models in planning provide decision makers involved in cultural heritage management with virtual environments and designs that can be realistic, analytical, navigable, interactive and allowing quick visualization of potential changes. Beyond that, tourism planners can create efficient working environments where they can communicate and interact effectively with all tourism stakeholders. With the vision and goals unity to be formed in these working environments, planning and management of the sustainable development of cultural heritage will become more possible.

One of the advantages of using VR for participants planning lies in a fact that "it offers a way for individuals from diverse backgrounds to communicate through a visual language that mimics the way people interact with the environment in the real world" (Al-Kodmany, 2002., p. 199). VR can be used in several ways in order to communicate tourism plans. For example, visual, interactive environments can be created to discuss tourism plans among relevant authorities, professionals or experts. Moreover, local people will be able to access these environments freely. By developing cultural heritage for the touristic purposes, it can be virtually incorporated into current landscape. In this manner, all stakeholders will be able to have a complete insight into how will the planned changes look like. For example, one museum will be able to test the potential demand for a special exhibition, or, management of one national park will be able to measure effects of cultural heritage, used in tourism purposes, on environment and local people. It can simulate pricing and timing strategies in order to reduce the negative impact of overuse of cultural heritage used in tourism purposes.

The list of heritage sites, that are virtually accessible, is constantly expanding. Numerous cultural heritage elements from different cultures and tourism destinations around the world have been digitized. By using 3D scanning devices cultural heritage sites and objects can be converted into digital form or virtual 3D models (Cignoni \& Scopigno, 2008). Such models can be a valuable tool for preserving the heritage, since they are cost and time-effective and allow indefinite storage of highly precise data sets. Although a cultural heritage site 
or object may suffer from effects such as erosion, VR model can provide precise information about its previous form, track the degradation level or assist in making restoration plans. It can also assist in monitoring or visualizing the effects of potential restorative actions (Guttentag, 2010).

It is believed that with dissemination of realistic experiences offered by VR application, the visitors' pressure on areas of cultural heritage, that are having difficulties to cope with real tourism demand, will decrease (Cheong, 1995). Cheong (1995) proposes that instead of putting the original cultural heritage at risk of attrition, virtual tours can actually help at protecting it by allowing visitors to access its simulation.

Benefit of VR for tourism marketing is primarily based on its ability to provide comprehensive set of cognitive and emotional information to potential tourists. One of the main characteristics of tourism product is that it cannot be tested before its consumption. Internet customers are buying this product based on the current descriptive information found on regarding web pages. In this context, nature of VR comes out as the most appropriate tool for providing customers with rich data, in order to assist them in obtaining the necessary information about the certain tourism product. Virtual destination tours prepared through VR applications are increasing the odds for customers' conscious decision making. Tourists, who use system that hosts VR applications, are able to make more conscious decisions and have more realistic expectations of a satisfying holiday (Hobson \& Williams, 1995). Virtual reality applications related to museums, which are one of the most important and visible exhibitions of cultural heritage in social media, may increase the interest in real visits to these places. In addition, VR applications are providing a unique platform for informative communication among tourists. There are growing opportunities to use VR applications in online travel communities, where tourists exchange information via online forums (Guttentag, 2010).

Besides being used as a tool for tourism marketing, VR systems itself can be directly marketed as entertainment touristic places. With this aspect, it creates important opportunities for the promotion of cultural heritage. For example, tourists could be able to walk virtually around Antalya's famous Phaselis national park. Through simulations, visitors can virtually experience tangible and intangible cultural heritage of this ancient city. Theme parks are often using VR applications to enhance customers' experience. Universal Studio in Florida States in USA is one of good examples. Promotion potential of VR can be used in museums, heritage areas and other touristic places. VR can be used as a unique platform for providing more of necessary information of places and objects that are of interest for the tourist in the area they visit, as well as a research tool.

VR applications increase the "accessibility" towards tourists. This access is limited by the virtual world. For example, one destination can be very far away, very expensive, very dangerous or even totally disappear. In these scenarios, one of the best alternatives is to allow the access to historical objects, which cannot be accessed in a real world, through virtual models.

Importance of VR for participation of disabled individuals in tourism activities is tremendous. Persons with disabilities who travel or want to travel form a generally neglected market segment. Unfortunately, there are a number of, sometimes, insurmountable obstacles that these segments are facing such as incompatible architecture with inappropriate visiting routes that makes transportation difficult and more complicated, as well as negative attitudes towards them (Çizel \& Çizel, 2014). Management of historical environment has the necessity to make balance between conservation of cultural heritage, but at the same time allowing public access to all visitors' segments. Accordingly, assessing the success of this process was also being investigated (Goodall et.al., 2014). With cooperation of tourism stakeholders and providers some physical barriers at heritage sites can be easily eliminated, while in some cases large costs or different protection requirement prevent change of physical properties towards meeting the needs of disabled visitors. In these circumstances, VR applications can provide alternative form of access for disabled visitors.

\section{CONCLUSION}

It is foreseen that virtual reality technologies will lead to revolutionary changes in the tourism industry. Benefits of the current VR applications for tourism industry were shortly summarized above. As the technology evolves, these benefits have the potential to increase as well. One of the main discussions in this field is whether travels that occur in the virtual reality will be able to replace the real travel experience, and it does not 
seem as if this discussion will end soon. Authors' opinion on this matter is that although VR has the ability to change and enhance the travel experience, it still cannot completely replace the emotions that arise when we meet with new people at destination, smells that we sense while walking down the street as well as the taste in the mouth when we enjoy in culinary specialties of visited destination. Because of this, instead of taking the place of a real travel, it provides more of complementary technological benefits. However, one should not forget about the disabled segments of societies since they are unable to easily travel on their own. With these segments VR applications have the potential to create an alternative and the closes-to-real travel experiences.

VR is playing an active role in sustainable management and protection of cultural heritage. As it can be seen from the examples given in current study, while VR technologies are assisting in active promotion of cultural heritage, at the same time it can be used to lower the pressure of the intensive use of cultural heritage at the destination. When used in the tourism context, VR can provide significant technological opportunities for establishing protection-usage balance of the related cultural heritage.

User-generated-videos (UGV) have become an important source of information used by potential tourists (Ertimur \& Gilly 2012; Hautz, et al, 2014). Research studies have shown that, especially members of Generation Y, have more trust in UGV than in the professional videos. Therefore, VR applications used in this area are increasing the effects of UGV.

It can be concluded that virtual reality applications will have an important role in future tourism developments. In line with the technological developments, the demands and expectations of future tourists will determine whether these technologies, which will provide significant benefits to the tourism industry, will replace the existing tourism products and services.

\section{REFERENCES}

Al-Kodmany, K. (2002). Visualization Tools and Methods in Community Planning: From Freehand Sketches to Virtual Reality. Journal of Planning Literature, 17(2), 189-211. DOI:10.1177/088541202762475946

Cheong, R. (1995). The Virtual Threat to Travel and Tourism. Tourism Management, 16(6), 417-422. DOI:10.1016/ 0261-5177(95)00049-T

Cignoni, P., \& Scopigno, R. (2008). Sampled 3D models for CH applications: a viable and enabling new medium or just a technological exercise? ACM Journal on Computing and Cultural Heritage, 1(1), 2-23. DOI:10.1145/1367080.1367082

Çizel B., \& Çizel R. (2014) Engellilerin Turizm Kısıtları ve Turist Olma İlişkisinde Aracı Değişkenler: Motivasyon Gücü ve Öğrenilmiş Çaresizlik, Anatolia Turizm Araştırmaları Dergisi, 25(1), 176-189.

Dewailly, J. M. (1999). Sustainable tourist space: from reality to virtual reality? Tourism Geographies, 1(1), 41-55. DOI:10.1080/14616689908721293

Ertimur, B., \& Mary C. G. (2012). So What Do You Think? Consumers Create Ads and Other Consumers Critique Them. Journal of Interactive Marketing, 26(3), 115-30. DOI:10.1016/j.intmar.2011.10.002

Goodall, B., Pottinger, G., Dixon, T., \& Russell, H. (2004). Heritage property, tourism and the UK Disability Discrimination Act. Property Management, 22(5), 345-357. DOI:10.1108/02637470410570734

Guttentag, D. A. (2010). Virtual Reality: Applications and Implications for Tourism. Tourism Management, 31(5), 637-651. DOI:10.1016/j.tourman.2009.07.003

Hautz, J., Fuller, J., Hutter, K., \& Thürridl, C. (2014). Let Users Generate Your Video Ads? The Impact of Video Source and Quality on Consumers' Perceptions and Intended Behaviors. Journal of Interactive Marketing, 28, 1-15. DOI:10.1016/j.intmar.2013.06.003

Hobson, J. S. P., \& Williams, A. P. (1995). Virtual Reality: A New Horizon for the Tourism Industry. Journal of Vacation Marketing, 1(2), 125-136. DOI:10.1177/135676679500100202

ICOMOS. (2002). ICOMOS international cultural tourism charter: Principles and guidelines for managing tourism at places of cultural and heritage significance. Australia: International Committee on Cultural Tourism. 